\title{
Acid, motility, and ulcers: a comparison of cisapride with placebo in the prevention of duodenal ulcer relapse
}

\author{
D D Kerrigan, M E Taylor, N W Read, A G Johnson
}

\begin{abstract}
In a single centre double blind study of 66 patients, the value of cisapride $(10 \mathrm{mg}$ twice daily) was compared with placebo in the prevention of duodenal ulcer relapse. Patients who remained ulcer free attended for clinical review every two months and had a mandatory endoscopy at $0,4,8$, and 12 months or if symptoms suggestive of ulcer recurrence developed. The 12 month crude relapse rates (that underestimate the probability of ulcer recurrence) showed that cisapride was superior to placebo $(34 \%(11 / 32)$ relapsed on cisapride $v 68 \%(23 / 34)$ on placebo, $\mathrm{p}=0.007)$. This finding was confirmed using lifetable analysis, with a $35 \%$ reduction $(95 \%$ confidence intervals $10-59 \%, p<0.05$ ) in the proportion of ulcer relapses in patients who had received cisapride compared with those treated with placebo. These results are similar to those reported in maintenance trials of $\mathbf{H}_{2}$ receptor antagonists analysed by the same method. Drug related adverse clinical events were mainly trivial, but led to three patients on cisapride and one on placebo withdrawing from the trial.

(Gut 1993; 34: 1042-1046)
\end{abstract}

Although duodenal ulcers rarely form in patients with achlorhydria, the widely held belief that all patients with duodenal ulcer disease secrete excessive amounts of acid is incorrect. About two thirds of duodenal ulcer patients have normal values of stimulated gastric secretion. ${ }^{1}$ It therefore follows that the therapeutic success of drugs that reduce gastric secretion might be explained if duodenal ulcers resulted from duodenal rather than gastric hyperacidity, possibly as a result of inadequate clearance of even normal amounts of acid from the bulb. We have suggested ${ }^{2}$ that properly coordinated motility might be of crucial importance in promoting acid clearance, and could therefore be an unrecognised factor in the pathogenesis of duodenal ulceration. If this hypothesis was correct, drugs that modulate upper gastrointestinal motility may have a role in the treatment of duodenal ulcer patients.

Nearly 20 years ago, Moshal presented data from a controlled trial that investigated the value of metoclopramide in the prevention of duodenal ulcer symptoms. ${ }^{3}$ Although maintenance treatment with metoclopramide significantly reduced the crude relapse rate of ulcer symptoms compared with placebo, Moshal's work (which was published shortly before the first placebo controlled trial of an $\mathrm{H}_{2}$ receptor antagonist), ${ }^{+}$has largely been forgotten. The aim of our study was to find out if the more potent prokinetic drug cisapride could prevent duodenal ulcer relapse. Cisapride (Prepulsid, Janssen Pharmaceutica, Beerse, Belgium) stimulates coordinated upper gastrointestinal motility ${ }^{56}$ particularly in patients with disordered motor patterns..$^{7-14}$ Cisapride does not affect gastric secretion either in animals ${ }^{1516}$ or man. ${ }^{17}$

\section{Patients and methods}

Patients aged between 18 and 75 years presenting to the Royal Hallamshire Hospital, Sheffield with duodenal ulceration were treated medically and had an endoscopy to confirm ulcer healing. They were then immediately entered into a single centre double blind trial in which they were randomised to receive either oral cisapride $10 \mathrm{mg}$ twice daily or an identical placebo tablet for up to 55 weeks. Ulceration associated with the use of non-steroidal anti-inflammatory drugs or steroids was excluded from the study, as were patients with a high alcohol intake $(>40 \mathrm{U} /$ week), or a history of surgery or drug use which might interfere with gastric secretion or motility. Patients with severe cardiorespiratory, renal, hepatic, neurological, or malignant disease were also excluded, together with women of childbearing age not using a reliable means of contraception.

Patients were reviewed every two months and the duodenum inspected endoscopically at the beginning of the trial, at approximately 4,8 , and 12 months, and if the patient developed recurrent dyspepsia that persisted after three days of simple antacid treatment (Maalox, maximum 30 tablets per month). Treatment failure was defined as evidence by endoscopy of a recurrent duodenal ulcer crater. At each visit, any unused tablets were returned to check on compliance and a new prescription issued. Adequate compliance was defined as ingestion of at least $70 \%$ of the tablets prescribed.

This study received approval from our local Ethical Committee and all patients provided written, informed consent.

\section{STATISTICAL METHODS}

Lifetable analysis - In a study of this kind, it is rarely possible to follow up every patient until they either relapse or successfully complete the trial. To overcome this difficulty, the estimated cumulative proportion of ulcers relapsing on each treatment was calculated using life tables and the log rank test as described by Peto et $a l^{1819}$ because this method uses the actual duration of the ulcer free period for each patient and allows 
TABLE I Patient characteristics on entry

\begin{tabular}{lll}
\hline & $\begin{array}{l}\text { Cisapride } \\
(n=32)\end{array}$ & $\begin{array}{c}\text { Placebo } \\
(n=34)\end{array}$ \\
\hline Age (y), mean (SD) & $46 \cdot 8(13)$ & $47 \cdot 9(14)$ \\
Sex (\% men) & $72 \%$ & $74 \%$ \\
Smokers & 16 & \\
Total & 10 & 16 \\
>10/day & $3 \cdot 5(0-12)$ & $6(0-12)$ \\
Alcohol (units/week) median (IQ & \\
range $)^{\star}$ & 3 & 5 \\
Duration of ulcer symptoms before randomisation & \\
<3 months & 5 & 6 \\
3-12 months & 8 & 8 \\
1-5 years & 16 & 15 \\
>5 years & 28 & \\
Healing drug & 0 & 24 \\
H 2 receptor antagonist & 4 & 1 \\
Bismuth subcitrate & 9 \\
Cisapride & 24 & 28 \\
Duration of healing treatment before randomisation & \\
<8 weeks & 7 & 3 \\
8-12 weeks & 1 & 0 \\
3-6 months & 0 & \\
>6 months & &
\end{tabular}

*One unit of alcohol = one half pint beer/lager, one glass of wine, a single measure of spirits. Cisapride $v$ placebo, $\mathrm{p}=0.70$ (MannWhitney U test).

any censored data to be incorporated into the calculation up to the point at which the patient drops out of the trial. In addition, as the efficacy of a drug can only be assessed accurately when viewed within the context of the associated placebo response, we also calculated the difference between the estimated proportion of patients who had relapsed on each treatment at $26,38,51$, and 55 weeks, together with the $95 \%$ confidence interval for this difference. The 51 week interval was chosen because there were insufficient $(\mathrm{n}<10)$ patients remaining beyond this time to allow accurate statistical analysis ${ }^{202}$ (see below). The 55 week interval represents the longest time that any patient remained in the trial.

Crude analysis - The crude percentage of patients whose ulcers had relapsed was also calculated to allow a comparison with some previously published trials, although it should be stressed that this method underestimates the true relapse rate. Crude relapse rates were calculated for each treatment using the method suggested by Kurata, ${ }^{22}$ ( $100 \times$ number of relapses detected in 12 months, divided by the number recruited) and were compared using a $\chi^{2}$ test.

\section{Results}

Of the 68 patients entered, two were retrospectively excluded from analysis: one patient had an incompletely healed ulcer at the time of entry, and the other had a substantial prepyloric ulcer

TABLE II Patient progress

\begin{tabular}{lcc}
\hline & Cisapride & Placebo \\
\hline Randomised & 34 & 34 \\
Exclusions & 2 & 0 \\
Valid entry & 32 & 34 \\
Withdrawn & 2 & 1 \\
$\quad$ Protocol violation & 3 & 0 \\
Defaulted & 3 & 1 \\
Drug related adverse events & 2 & 1 \\
\hline Other adverse events & 2 & \\
\hline
\end{tabular}

*Traced and interviewed by telephone >one year after leaving trial. All three patients had remained asymptomatic and none had received further treatment for dyspepsia. associated with small duodenal erosions. Thirty two of the remaining patients were randomised to receive cisapride, and 34 to receive placebo.

\section{PATIENT CHARACTERISTICS}

Patients randomised to each treatment were well matched for age, sex, smoking habit, alcohol intake, the duration of their previous dyspeptic symptoms, and their previous responsiveness to medical treatment (Table I). Most acute ulcers had been healed by $\mathrm{H}_{2}$ receptor antagonists, and only one patient (randomised to placebo) had received bismuth subcitrate before entering the trial. Three patients (two randomised to cisapride) had originally presented with large or multiple chronic duodenal ulcers associated with small solitary areas of slough on either the incisura or in the prepyloric region. A check on the number of tablets returned at each visit showed that all patients took at least $70 \%$ of the tablets prescribed, and that the median (interquartile range) number of antacid tablets consumed per week was similar in both groups (cisapride $2.2(0 \cdot 1-5 \cdot 7)$; placebo $1.9(0 \cdot 3-3 \cdot 6)$ : $\mathrm{p}=0 \cdot 76$, Mann-Whitney U test).

\section{WITHDRAWALS}

In addition to the two patients excluded from analysis, another 13 patients were withdrawn from the study (Table II). Three failed to comply with the protocol restrictions; one patient continued to use $\mathrm{H}_{2}$ receptor antagonists until she was withdrawn three days after entry and another was unable to keep his alcohol consumption below $40 \mathrm{U} /$ week; a third (asymptomatic) patient withdrew her consent within a month of randomisation. In addition, 10 patients were withdrawn because they either defaulted from follow up $(n=3$, all had moved away from the Sheffield area), or because they developed an adverse clinical event $(n=7)$ which led to a change in their treatment (Table III). The reported occurrence of minor drug related symptoms ( - that is, not severe enough to warrant withdrawal from the study), was similar in each group (Table III). Ten of the 13 patients withdrawn were in the group receiving cisapride (Table II).

\section{TABLE III Adverse clinical events}

\begin{tabular}{lll} 
& Cisapride & Placebo \\
\hline Clinical events resulting in withdrawal & & \\
Drug related & & \\
$\quad$ Maculopapular rash & 1 & 0 \\
$\quad$ Vomiting & 1 & 0 \\
$\quad$ Previous loose bowel habit worsened & 1 & 0 \\
$\quad$ Epigastric fluttering sensation & 0 & 1 \\
Non drug related & $1 \star$ & 0 \\
$\quad$ Severe psoriatic eruption & $1 \dagger$ & $1 \ddagger$ \\
$\quad$ Abdominal pain & & 2 \\
Minor adverse events (patient not withdrawn) & 4 & 2 \\
Increased bowel frequency (>3/day) & 3 & 4 \\
$\quad$ Abose stools & 7 & 4 \\
$\quad$ Headachinal cramp & 1 & 3 \\
Dizziness & 2 & 2 \\
\hline
\end{tabular}

^Developed nine months after starting cisapride, all drugs discontinued; tendoscopy showed duodenitis, but no evidence of ulcer recurrence; łdiscontinued treatment after pain developed, but did not contact us for endoscopy; §figures refer to number of events reported (some patients experienced $>1$ symptom). 
TABLE IV Relative efficacy of cisapride and placebo in preventing duodenal ulcer relapse after 6, 9, and 12 months of treatment

26 weeks $(95 \% \mathrm{CI})$

38 weeks $(95 \% \mathrm{CI})$

51 weeks $(95 \%$ CI)

55 weeks $(95 \% \mathrm{CI})$

$+14 \%(-11$ to $+40 \%)$ $+27 \%(+2$ to $+52 \%)$ $+35 \%(+10$ to $+59 \%)$ $+26 \%(-9$ to $+60 \%)$

Positive values indicate an increased estimated $\%$ ulcer free 'survival' with cisapride treatment compared with placebo; negative values indicate decreased 'survival' with cisapride.

$\star$ Denotes statistical significance at least at the $5 \%$ value.

\section{ULCER RECURRENCE}

Of the 34 recurrent duodenal ulcers detected, 23 $(68 \%)$ occurred in patients taking placebo, most recurrences being picked up at the scheduled 4, 8 , and 12 month endoscopies (15/23 placebo, $7 / 11$ cisapride). Interestingly, although relapse on maintenance cisapride was almost invariably symptomatic $(10 / 11)$, one third $(8 / 23)$ of the placebo relapses were silent. The crude 12 month relapse rate was lower in patients treated with cisapride $(11 / 32,34 \%)$ compared with those who received placebo $\left(23 / 34,68 \%\left(\chi^{2}=7 \cdot 306\right.\right.$, $\mathrm{p}=0.007))$. It should be emphasised, however, that the crude rate is probably an underestimate of the true proportion of recurrent ulcers, because it assumes that patients who were withdrawn (and therefore not followed up endoscopically for the entire 12 months) did not develop an ulcer relapse.

A more accurate analysis of ulcer recurrence can be derived using lifetable analysis. Maintenance treatment with cisapride was associated with a significant increase in ulcer free survival at week 38 (Table IV), and a $35 \%$ increase in ulcer free survival at week 51 (estimated proportion relapsing on placebo $=72 \%(95 \%$ CI $55-88 \%) v$ cisapride $=37 \%(95 \%$ CI 19-55\%), $\mathrm{p}<0.05))$. However, the particularly wide $95 \%$ confidence interval for the difference between the percentage of cisapride and placebo treated patients estimated to remain ulcer free at 55 weeks (Table IV), reflects the inherent inaccuracy of this portion of the survival curve when the number of patients remaining was small.

The figure illustrates the cumulative ulcer free survival curves of patients randomised to each drug. As stated earlier, it is easy to misinterpret the unreliable later part of the curve (for example, the sharp decrease in the estimated ulcer free survival of patients treated with cisapride that occurred at week 52 resulted from

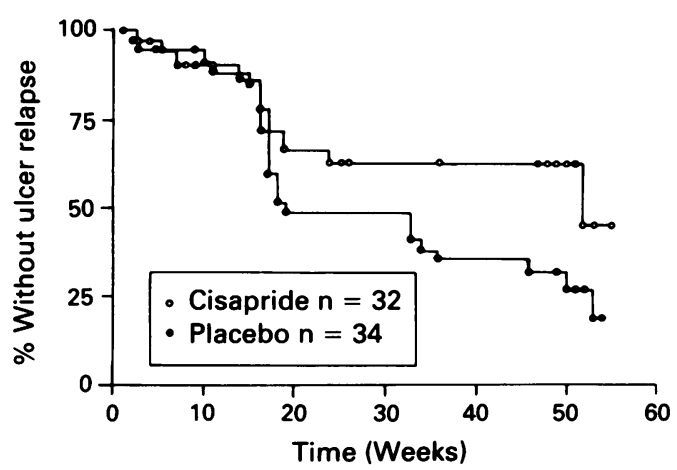

Cumulative ulcer free 'survival' curves for patients treated with maintenance cisapride $(\bigcirc)$ and placebo $(O)$. a single ulcer recurrence). To avoid this kind of error, survival analysis was truncated at week 51 , the point at which an adequate number $(n>10)$ of patients were still present. ${ }^{2021}$ Lifetable analysis of the truncated survival curve (which excludes one placebo and one cisapride recurrence) also indicates that patients taking cisapride were less likely to develop a recurrent ulcer over the study period than those receiving placebo $\left(\chi^{2}=3.673, p=0.055 \log\right.$ rank test $)$.

\section{Discussion}

The results of this single centre pilot study show that maintenance treatment with cisapride $10 \mathrm{mg}$ twice daily can reduce the likelihood of duodenal ulcer relapse. Lifetable analysis shows that 37\% (95\% CI 19-55\%) of patients receiving cisapride are liable to develop a recurrent ulcer after 51 weeks of treatment, compared with $72 \%$ (95\% CI $55-88 \%$ ) of those randomised to placebo (complete separation of $95 \%$ confidence intervals). This estimated rate of ulcer recurrence is similar to that reported in lifetable analyses of other maintenance trials using both cimetidine $400 \mathrm{mg}$ once daily (median annual recurrence reported = $31 \%$, range $21-55 \%)^{23-28}$ and ranitidine $150 \mathrm{mg}$ once daily (median annual recurrence reported = $35 \%$, range $18-49 \%)^{21242729-32}$ Although other reports of maintenance treatment with $\mathrm{H}_{2}$ receptor antagonists have yielded superior results (15-39\% annual recurrence),,$^{22} 2333-37$ these studies only reported crude relapse rates (which underestimate the true rate of ulcer recurrence), or contained extraordinary inconsistencies in the presentation and interpretation of the trial data. ${ }^{23} 37$

A direct comparison of the relative efficacy of ulcer maintenance drugs is hampered by discrepancies in the reported frequency of placebo related ulcer relapses, presumably because of geographical variation in the aggressiveness of duodenal ulcer disease. To overcome this problem, it is necessary to view the apparent success of an active drug in the context of the parallel placebo response. After 51 weeks of treatment, cisapride reduced the likelihood of duodenal ulcer relapse by $35 \%(95 \%$ CI 10-59\%) compared with placebo $(\mathrm{p}<0 \cdot 05)$. Comparable data from $\mathrm{H}_{2}$ receptor antagonist maintenance trials are limited, but would seem to be similar for both cimitidine $\mathbf{4 0 0} \mathrm{mg}$ once daily (estimated reduction in duodenal ulcer relapse rate compared with placebo ranges from $26 \%^{26}$ to $37 \%{ }^{25}$ ), ranitidine $150 \mathrm{mg}$ once daily (estimated reductions of $24 \%,{ }^{32} 39 \%^{22}$ and $48 \%{ }^{31}$ ) and famotidine $20-40 \mathrm{mg}$ once daily (estimated $32-34 \%$ reduction in relapse rate $\left.{ }^{38}\right)$.

Most ulcer maintenance trials, including this study, contain several potential methodological weaknesses that merit further discussion. Firstly, because patients who developed recurrent dyspepsia had another endoscopy before their next scheduled endoscopy, an unacceptable degree of bias could be introduced if the ulcer relapse rates associated with two drugs were identical, but relapses on one treatment resulted in more severe symptoms than those on the other. As some $\mathrm{H}_{2}$ receptor antagonist maintenance trials have reported a greater proportion of 
symptomatic ulcer recurrences in patients randomised to placebo, it would be easy to overestimate the placebo relapse rate. Secondly, the definition of treatment failure, which included both symptomatic and asymptomatic relapses needs to be discussed. It has been argued that the detection rate of asymptomatic recurrences depends on the frequency of scheduled endoscopic examinations, ${ }^{39}$ and that infrequent endoscopy might allow some asymptomatic ulcers to reheal without being detected. If, as intimated earlier, the proportion of asymptomatic recurrences was greater in the active treatment group, this could also lead to bias, and underestimation of the frequency of cisapride recurrences relative to placebo.

Although worthy of consideration, we feel that neither of these objections challenge the conclusions of this study. Endoscopic surveillance of treated and untreated asymptomatic ulcers has indicated that $75 \%$ persist unhealed over many months,${ }^{40}$ and so it is unlikely that an endoscopy every four months would have missed many. Moreover, the proportion of ulcer recurrences detected at unscheduled endoscopies was the same in cisapride and placebo treated patients (35-36\%) and in contrast with the $\mathrm{H}_{2}$ receptor antagonist maintenance trials, symptomatic recurrence in this study was particularly common in the group randomised to cisapride, not placebo. If anything, this would suggest that we actually overestimated the frequency of cisapride relapses, and underestimated the placebo relapse rate. One group of investigators have argued that the inclusion of asymptomatic recurrences in the analysis of ulcer relapse trials should be discouraged, because these silent ulcers are clinically irrelevant; ${ }^{394}$ however, such optimism (based on findings made in a small group of patients with asymptomatic ulceration followed up for between 1 and 13 months) is probably misguided, because one third of duodenal ulcer patients presenting with perforation ${ }^{42-44}$ and up to $60 \%$ admitted with haematemesis or melaena, or both ${ }^{45}$ do not give a history of previous ulcer pain.

In the absence of any significant anti-secretory effects, ${ }^{15-17}$ it seems likely that the beneficial action of cisapride reported in this study results from its prokinetic qualities, which might enhance the clearance of acidic gastric effluent from the bulb, and thereby reduce its duration of contact with the duodenal mucosa. Our finding that patients with healed duodenal ulcers have disordered patterns of antroduodenal motility, which could promote sequestration of acid within the bulb, ${ }^{2}$ provides indirect support for this hypothesis, as do preliminary reports that cisapride $10 \mathrm{mg}$ three times daily reduces $24 \mathrm{~h}$ intraduodenal acidity in healthy volunteers without affecting gastric $\mathrm{pH} .{ }^{47}$ Cisapride is also thought to exert an inhibitory effect on the possum sphincter of Oddi, ${ }^{48}$ and might thereby enhance bile flow into the duodenum. Despite the current interest in the pathogenic potential of Helicobacter pylori ( $H$ pylori), the question of whether or not motility and cisapride effect $H$ pylori colonisation has not been resolved, although sketchy data are available that show that patients with dyspepsia infected with the organism have more rapid gastric emptying than healthy $H$ pylori negative controls. ${ }^{49}$

The close relation between acid and duodenal ulceration was recognised in the early part of this century, ${ }^{50}$ and until recently, attempts to provide a cure for 'peptic' ulcer disease have focused almost exclusively on the development of drugs and surgical procedures that inhibit or abolish gastric secretion, even though contemporary findings show that only $20-50 \%$ of duodenal ulcer patients actually secrete excessive amounts of acid. ${ }^{1}$ It is becoming increasingly apparent that drugs, which act through mechanisms other than acid inhibition, can control duodenal ulcer disease as effectively as $\mathrm{H}_{2}$ receptor antagonists; the findings of this study suggest that stimulation of normal gastroduodenal motility (and thus acid clearance from the bulb) may be an important mechanism in this respect, but one which has received scant attention to date.

We wish to acknowledge financial support provided by the Janssen We wish to acknowledge financial support provided by the Janssen Research Foundation, and are particularly grateful to their representatives $P$ Welburn, T Heggie, J Turner, L Legg, and $K$
Hutchinson. We are also grateful to Dr R A Dixon, Department of Public Health Medicine, University of Sheffield for his advice on the statistical analysis of the final data.

An outline of this paper appeared as abstracts in Gastroenterology 1989; 96: A254 and Gut 1989; 30: A1489-90.

1 Lam SK. Pathogenesis and pathophysiology of duodenal ulcer. In: Isenberg JI, Johansson C, eds. Clinics in gastroenterology - Peptic ulcer disease. Vol 13. No 2. Philadelphia: Saunders, 1984: 447-72.

2 Kerrigan DD, Read NW, Houghton LA, Taylor ME, Johnson AG. Disturbed gastroduodenal motility in patients with active and healed duodenal ulceration. Gastroenterology 1991; 100: 892-900.

3 Moshal MG. Trials with metoclopramide in duodenal ulceration. Postgrad Med f 1973; 49 (suppl 4): 100-3.

4 Pounder RE, Williams JG, Milton-Thompson GJ, Misiewicz JJ. Relief of duodenal ulcer symptoms by oral metiamide. BMF 1975; 2: 307-9.

5 Stacher G, Gaupmann G, Mittelbach G, Schneider C, Steinringer H, Langer B. Effects of oral cisapride on interdigestive jejunal motor activity, psychomotor function and side-effect profile in healthy man. Dig Dis Sci 1987; 32: 1223-30.

6 Coremans G, Janssens J, Vantrappen G, Chaussade S, Ceccatelli $P$. Cisapride stimulates propulsive motility patterns in human jejunum. Dig Dis Sci 1988; 33: 1512-9.

Camilleri M, Brown ML, Malagelada JR. Impaired transit of chyme in chronic intestinal pseudo-obstruction.
by cisapride. Gastroenterology 1986; 91: 619-26.

8 Jian R, Ducrot F, Piedeloup C, Mary JY, Najean Y, Bernier JJ. Measurement of gastric emptying in dyspeptic patients: JJ. Measurement of gastric emptying in dyspeptic patients: effect of a

9 Corinaldesi R, Stanghellini V, Raiti C, Rea E, Salgemini R, Barbara L. Effect of chronic administration of cisapride on gastric emptying of a solid meal and on dyspeptic symptoms in patients with idiopathic gastroparesis. Gut 1987; 28: $300-5$.

10 Stacher G, Bergmann H, Wiensnagrotzki S, Kiss A, Schneider C, Mittelbach G, et al. Intravenous cisapride accelerates delayed gastric emptying and increases antral contraction amplitude in patients with primary anorexia nervosa. Gastroenterology 1987; 92: 1000-6.

11 Havelund T, Oster-Jorgensen E, Eshoj O, Larsen ML, Lauritsen $K$. Effects of cisapride on gastroparesis in patients Lauritsen K. Effects of cisapride on gastroparesis in patients with insulin-dependant diabetes mellitus. A doub
controlled trial. Acta Med Scand 1987; 222: 339-43.

12 Urbain J-L, Siegel JA, Debie NC, Pauwels SP. Effect of cisapride on gastric emptying in dyspeptic patients. Dig Dis Sci 1988; 33: 779-83.

13 Ghigliani M, Iantorno G, Vazquez S, Varela A. Acute effect of the gastrokinetics cisapride and metoclopramide on the gastric emptying function in patients with the early satiety syndrome. Acta Gastroenterol Latinoam 1987; 17: 43-50.

14 Testoni PA, Bagnolo F, Fanti L, Passaretti S, Tittobello A. Long-term oral cisapride improves interdigestive antro-
duodenal motility in dyspetic patients. Gut 1990; 31: 288-90.

15 Bingham S, Andrews PLR. Preliminary studies on the mechanism of action of cisapride. Digestion 1986; 34: 138.

16 Schuurkes JAJ, Van Neuten JM. Animal pharmacology of the gastrointestinal prokinetic, cisapride. In: Johnson AG, Lux G, eds. Progress in the treatment of gastrointestinal motility disorders: the role of cisapride. Amsterdam: Excerpta Medica,

17 Muller-Lissner SA, Fraass C. Chronic oral treatment with cisapride decrease high bile salt reflux rates. $A m \mathcal{J}$ Gastroenterol 1986; 81: 354-7. 
18 Peto R, Pike MC, Armitage P, Breslow NE, Cox DR Howard SV, et al. Design and analysis of randomised clinical trials requiring prolonged observation of each patient. I Introduction and design. Br f Cancer 1976; 34: 585-612.

19 Peto R, Pike MC, Armitage P, Breslow NE, Cox DR, Howard $\mathrm{SV}$, et al. Design and analysis of randomised clinical trials requiring prolonged observation of each patient. II. Analysis requiring prolonged observation of each pa

20 Machin D, Gardner MJ. Calculating confidence intervals for survival time analyses. In: Gardner MJ, Altman DG, eds. Statistics with confidence - confidence intervals and statistical guidelines. London: British Medical Journal, 1989: 64-70.

21 Van Deventer GM, Elashoff JD, Reedy TJ, Schneidman D Walsh JH. A randomised study of maintenance therapy with ranitidine to prevent the recurrence of duodenal ulcer. NEnglf Med 1989; 320: 1113-9.

22 Kurata JH, Koch GG, Nogawa AN. Comparison of ranitidine and cimetidine ulcer maintenance therapy. $\mathcal{f}$ Clin Gastroenterol 1987; 9: 644-50

23 Silvis SE. Final report on the United States multicenter trial comparing ranitidine to cimetidine as maintenance therapy comparing ranitidine to cimetidine as maintenance therapy 1985; 7: 482-7.

24 Gough KR, Bardhan KD, Crowe JP, Korman MG, Lee FI, Reed PI, et al. Ranitidine and cimetidine in prevention of duodenal ulcer relapse. Lancet 1984; ii: 659-62.

25 Sonnenberg A, Schuurkes SA, Vogel E, Schmid P, Gonvers JJ, Peter P, et al. Predictors of duodenal ulcer healing and relapse. Gastroenterology 1981; 81: 1061-7.

26 Sontag S, Graham DY, Belsito A, Weiss J, Farley A, Grunt R, et al. Cimetidine, cigarette smoking and recurrence duodenal ulcer. N Engl 7 Med 1984; 311: 689-93.

27 Bresci G, Capria A, Federici G, Rindi G, Geloni M, Corsini G. Prevention of relapse with various antiulcer drugs. Scand $\mathscr{f}$ Grevention of relapse with various antiul

28 Bardhan KD, Hinchliffe RFC, Bose K. Low dose main tenance treatment with cimetidine in duodenal ulce intermediate-term results. Postgrad Med F 1986; 62: 347-51.

29 Boyd EJS, Wilson JA, Wormsley KG. Effects of treatmen compliance and overnight gastric secretion on outcome of maintenance therapy of duodenal ulcer with ranitidine. Scand 7 Gastroenterol 1983; 18: 193-200.

30 Boyd EJS, Wilson JA, Wormsley KG. Safety of ranitidine maintenance treatment of duodenal ulcer. Scand $\mathcal{F}$

31 Witzel L, Ansari A, Blum AL, Merki H. Comparison of maintenance treatment versus intermittent treatment with ranitidine in preventing duodenal ulcers. Gastroenterol 1990 98: A149.

32 Kozarek R, Berenson M, Berkowitz J, Bright-Asare P, DeLuca V, Font R, et al. Maintenance therapy with ranitidine following healing of acute duodenal ulcer. Cur Therap Res 1985; 38: 341-51.
33 Freston JW. H2-receptor antagonists and duodenal ulcer recurrence: analysis of efficacy and commentary on safety, costs and patient selection. Am $\mathcal{F}$ Gastroenterol 1987; 82: costs and

34 Bodemar G, Walan A. Maintenance treatment of recurren peptic ulcer by cimetidine. Lancet 1978 ; i: 403-7.

35 Strom M, Berstad A, Bodemar G, Walan A Results of short and long-term cimetidine treatment in patients with juxtapyloric ulcers, with special reference to gastric acid an pepsin secretion. Scand $\mathcal{F}$ Gastroenterol 1986; 21: 521-30.

36 Alstead EM, Ryan FP, Holdsworth CD, Ashton MG, Moor $M$. Ranitidine in the prevention of gastric and duodenal ulcer relapse. Gut 1983; 24: 418-20.

37 Silvis SE. Results of the United States ranitidine maintenance trials. Am F Med 1984; 77 (suppl 5B): 33-8.

38 Texter EC, Navab F, Mantell G, Berman R. Maintenance therapy of duodenal ulcer with famotidine. A multicenter .

39 Boyd EJS, Penston JG, Johnson DA, Wormsley KG. Does maintenance therapy keep duodenal ulcers healed? Lancet 1988; i: 1324-7.

40 Boyd EJS, Wilson JA, Wormsley KG. The fate of asymptomatic recurrences of duodenal ulcer. Scand $\mathcal{F}$ Gastroentero $1984 ; 19 \cdot 808-12$.

41 Penston JG. Maintenance treatment versus no treatment in patients with duodenal ulcer disease. Scand $\mathcal{F}$ Gastroentero 1990; 25 (suppl 177): 42-51.

42 Mark JBD. Factors influencing the treatment of perforated duodenal ulcer. Surg Gynecol Obstet 1969; 129: 325-30.

43 Griffin GE, Organ CH. The natural history of the perforated duodenal ulcer treated by suture plication. Ann Surg 1976; 183: $382-5$

44 Drury JK, McKay AJ, Hutchinson JSF, Joffe SN. Natura history of perforated duodenal ulcers treated by suture plication. Lancet 1978; ii: 749-50.

45 Jorde R. Burhol PG. Asymptomatic peptic ulcer disease. Scand f Gastroentrol 1987; 22: 129-34.

46 Aucouturier JP, Renard P, Carteret E, Minault S, Zeitoun P. Are hemorrhagic gastro-duodenal ulcers frequently asymptomatic or associated with pain? Gastroenterology 1991; 100: A27

47 Weiser HF, Schippers E, Seebauer L. The effect of cisaprid on intraduodenal $\mathrm{pH}$ in man. Gastroenterology 1987; 92 1689 .

48 Baker RA, Saccone GTP, Toouli J. Contractile activity of the sphincter of Oddi and duodenum is inhibited by cisapride in the Australian brush-tailed possum in vitro. Gastroenterolog 1990; 98: A482.

49 Caldwell SH, Marshall BJ, Hoffman SR, Valenzuela G, McCallum RW. Does Helicobacter pylori gastritis change gastric emptying of a solid meal? Gastroenterology 1990; 98:

50 Schwarz C. Ueber penetrierende magen - und jejunalgeschwure. Beitr Klin Chir 1910; 67: 96-128. 